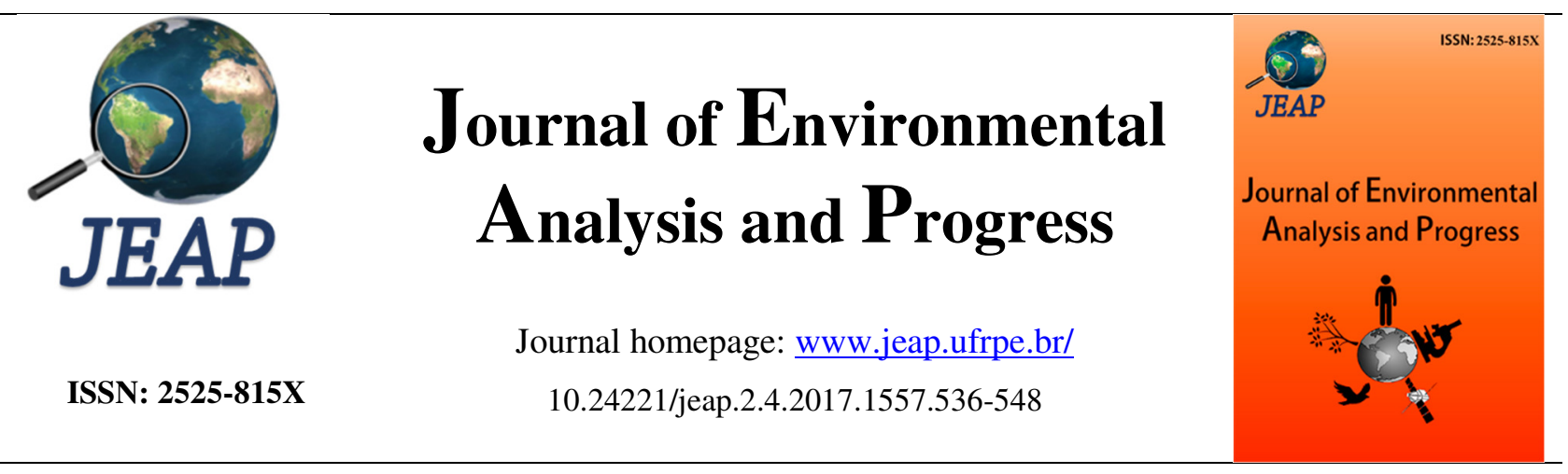

\title{
O uso da natureza em ações urbanísticas: a privatização do acesso ao solo em Recife-Brasil
}

\section{The use of nature in urban management: the privatization of land access in Recife-Brazil}

\author{
Cláudio Jorge Moura de Castilho ${ }^{\mathrm{a}}$, Amanda Cristina Perboire Emerenciano de Souza ${ }^{\mathrm{a}}$ \\ ${ }^{a}$ Universidade Federal de Pernambuco-UFPE, Avenida Acadêmico Hélio Ramos, s/n, Cidade Universitária. CEP: 50740- \\ 530. Recife-PE, Brasil. E-mail: claudiocastilho44@gmail.com, amaanda.souza@gmail.com.
}

\begin{abstract}
A R T I C L E I N F O
Recebido 04 Ago 2017

Aceito 28 Ago 2017

Publicado 19 Out 2017

A B S T R A C T

This article discusses the use of nature, through the problem of soil access in Recife, as an attempt to understand the complexity of society-nature relationships in the city. Aiming to operationalize this objective, a broad and open methodological approach was used based on the main results of a bibliographic review carried out in the construction of a research project about the subject. The main contribution of this paper resides in the fact that urban management must take into account the "principle of nature" as a collective good related to a permanent process of urban space production. Otherwise, the city spaces will become even more unsustainable to live. Keywords: Technical-instrumental rationality, environmental rationality, the right to the city, urban fights.

\begin{abstract}
R E S U M O
Neste artigo discute-se o uso da natureza, através do problema do acesso ao solo em Recife, na tentativa de compreender a complexidade das relações sociedade-natureza na cidade. Visando operacionalizar este objetivo, utilizou-se de uma abordagem metodológica ampla e aberta com base em resultados da revisão bibliográfica executada na construção de um projeto de pesquisa sobre o tema. Como principal contribuição, tem-se que a gestão urbana deve levar em conta o "princípio de natureza" como bem coletivo no processo permanente de produção do espaço urbano, senão os espaços das nossas cidades tornar-se-ão ainda mais insustentáveis à vida. Palavras-Chave: Racionalidade técnico-instrumental, racionalidade ambiental, direito à cidade, lutas urbanas.
\end{abstract}

\section{Introdução}

Seguindo uma linha de estudos, pesquisas e publicações acerca do problema da concepção e prática da natureza em políticas públicas, de cunho urbanístico, no âmbito do Grupo de Pesquisa Movimentos Sociais e Espaço Urbano (MSEU), pretende-se ressaltar a questão do desigual acesso ao solo em Recife, o qual cada vez mais é transformado em mercadoria pela lógica da racionalidade técnico-instrumental do capitalismo, hoje apresentando forte tendência neoliberal.
O solo constitui um bem essencial à vida de qualquer classe social nos espaços da cidade (e do campo); mas, em função principalmente dos imperativos da lógica da racionalidade supracitada, vem deixando de ser um bem coletivo para tornarse uma mercadoria a ser comercializada no mercado imobiliário para dar lucro, privatizando-o e, por conseguinte, retirando o direito dos homens e das mulheres pertencentes às classes sociais subalternas (aquelas "que vivem do seu trabalho") a também terem acesso ao solo. 
Até o momento atual, o MSEU tem se debruçado sobre estudos acerca do uso da água, do verde - da arborização - e dos ventos marítimos na cidade, proporcionando o acúmulo de informações interessantes para o que ocorre, por exemplo, no espaço urbano do Recife (Castilho, 2014; Pontes \& Castilho, 2016; Soeiro, Wertheimer, Bautista \& Castilho, 2016; Castilho \& Teixeira, 2016; Pontes, 2017).

Na pesquisa ora em apreço, parte-se do problema geral acima apresentado, mas elucidando-o através do acesso - e, por seu turno, do uso - ao solo urbano; mais especificamente através do acesso ao espaço, que reúne um conjunto de bens naturais - vistos pelo mercado imobiliário como mercadorias - dentre os quais se tem também o solo. O que será tratado com base na análise da consideração do seu papel em ações urbanísticas na cidade, as quais, cada vez mais, estão apresentando, de maneira mais patente, seu caráter higienista e gentrificador (Criekingen, 2006).

Seguindo este mesmo raciocínio, encontrase em desenvolvimento, atualmente, com incentivo da FACEPE, uma pesquisa de iniciação científica sobre o uso de bens "naturais" pelos agentes produtores do espaço urbano na cidade de Recife (Castilho \& Teixeira, 2016) e, neste sentido, foram produzidas duas dissertações de mestrado (Soeiro, 2017; Pontes, 2017) no Programa de PósGraduação em Desenvolvimento e Meio Ambiente/PRODEMA; a primeira com auxílio de uma bolsa concedida por esta mesma agência de fomento à pesquisa.

Com relação à questão do solo urbano, à primeira vista, não o enxergamos, apesar de nos localizarmos e de pisarmos nele todos os dias, negligenciando, assim, a sua relevância em nossa vida cotidiana. Da mesma maneira, talvez por não perceber sua importância na nossa vida, não nos importamos muito quando notamos processos de degradação do solo.

Com efeito, formado pela decomposição das rochas, em milhares de anos, os solos são desgastados em poucos anos, notadamente em lugares em que os imperativos da lógica da racionalidade técnico-instrumental capitalista são mais acelerados, a qual também tem afastado pessoas oriundas das classes sociais subalternas das áreas mais valorizadas da cidade. Isto tem acontecido pelo conjunto de agentes sociais que se está considerando neste artigo como Complexo Fundiário, Imobiliário, Comercial e Financeiro (CFICF) que busca apropriar-se de todos os solos da cidade que se valorizam, mesmo daqueles historicamente aterrados pelos moradores de baixa renda.
Compreende-se, portanto, solo, neste artigo, como a camada superficial sólida da crosta terrestre sobre a qual pisamos, construímos nossas habitações, circulamos e tecemos nossas relações sociais; neste sentido, pode-se considerá-lo, também, na cidade, como o chão no e a partir do qual a vida humana acontece. Isto, claro, além da sua clássica função de base das atividades agrícolas e de criação.

Porém, a ideia de se ter acesso ao solo - e como um bem coletivo a ser usado de maneira sustentável - sempre teve destaque na ciência, sobretudo em função da consciência da sua importância fundamental para a sociedade. Daí por que este bem é considerado por Oliveira (2017) como um dos mais importantes elementos constituidores das paisagens geográficas em qualquer lugar.

A relevância dos solos, assim, reside no fato de que este elemento natural constitui, ao mesmo tempo, suporte do conjunto das atividades humanas que acontecem, no caso ora em análise, no espaço urbano. Por este motivo sua importância havia sido destacada anteriormente, ainda que indiretamente, no início dos anos 1950, no âmbito de trabalhos sobre o processo de produção do espaço urbano em Recife. Mais precisamente, pela realização de constantes aterros pelos próprios moradores locais, sobretudo por aqueles oriundos das classes sociais subalternas.

Nesse sentido, começou-se a mostrar como os recifenses foram, paulatinamente, construindo seu solo, tendo que vencer as adversidades inerentes ao seu sítio urbano, tal como escrito por Castro (1954). Desse modo,

[...] a cidade se assenta nas terras baixas de uma extensa planície aluvionar que se estende desde as costas marinhas, frisadas, em quase toda a extensão por uma linha de arrecifes de pedra, até uma cadeia irregular de outeiros terciários, que envolvendo em semicírculos, a separa das terras onduladas do interior. É essa planície constituída de ilhas, penínsulas, alagados, mangues e paúis, envolvidos pelos braços de água dos rios que, rompendo passagem através da cinta sedimentar de colinas, se espraiam remansosos pela planície inundável. Foi nesses bancos de solo ainda mal consolidados - mistura ainda incerta de água e terra - que nasceu a cidade do Recife, chamada de cidade anfíbia, como Amsterdam e Veneza, porque assenta as massas de sua construção 
quase dentro da água, aparecendo numa perspectiva aérea, com os seus diferentes bairros flutuando esquecidos à flor das águas. (Castro, 1954, pp. 33-34)

Segundo Lins (1982, p. 84), ainda no que diz respeito à mesma questão, a evolução urbana em Recife aconteceu à medida que o seu sítio urbano, desprovido a priori de solo foi, paulatinamente, sendo aterrado.

A partir de todos esses compridos aterros cresceram os chãos de um lado e do outro. [...]. Durante a ocupação flamenga várias obras de aterro concorrem com retificações de trechos fluviais e de camboas e com a abertura de canais...

Daí resulta, sobretudo pelo trabalho humano investido no permanente processo de conquista de terras frente às águas, a valorização das áreas de terra firme, incluindo as aterradas pelas populações de baixa renda vinculadas às classes sociais subalternas. Com efeito, mesmo sem acesso às técnicas mais modernas de aterros empreendidas pelos gestores públicos locais, também as pessoas pertencentes às classes subalternas como se disse anteriormente aterraram áreas para levantar suas moradias, condição fundamental para fazerem parte da vida urbana. Razão pela qual, defende-se, que o povo recifense é quem deve ser considerado como o seu verdadeiro "proprietário".

Com isso, evidenciava-se que o espaço urbano em Recife se desenvolveu, paulatinamente, sobre uma gama de solos formado pela ação conjunta de diversos elementos, exercendo, cada qual, uma ação específica e contínua no âmbito do ambiente local.

Inicialmente, a planície flúvio-marinha era apenas uma enseada envolvida por colinas, onde esbarravam as vagas marítimas que conseguiam ultrapassar os arrecifes situados a leste da cidade em formação. Aí, portanto, desaguavam os dois principais rios recifenses, o Capibaribe e o Beberibe, os quais, durante as frequentes enchentes, transportavam dos seus próprios leitos e das suas margens, os sedimentos que, pouco a pouco, foram se acumulando no referido espaço.

Ao mesmo tempo,

A contribuição marítima se manteve presente de várias maneiras: no movimento lento, mas contínuo, das ondas do oceano atlântico e na velocidade das correntes, dificultando, assim, a volta na baixa mar, das partículas transportadas e sedimentadas na preamar; nas transgressões marinhas, ocorridas em momentos diversos, mas que carregam novos resíduos e também ampliavam a área de solo firme; ou ainda, na formação dos arrecifes, praias de restingas consolidadas pela junção de grãos de areia ao cimento natural, que funcionando como barreiras, impediam que os sedimentos retornassem nos movimentos das águas, entre outros (Barreto, 1994, p. 24).

Percebe-se, portanto, segundo esta mesma autora, que estudos dessa natureza são indispensáveis na tomada de qualquer decisão relativa ao acesso ao solo - pelo seu uso e ocupação - no espaço físico da cidade, uma vez que são as ações humanas que determinam as mudanças ambientais. Estas mudanças, por sua vez, repercutem diretamente na qualidade de vida, especificamente, quando o estudo se refere ao Recife - uma cidade que, como visto acima, se desenvolveu, no curso da sua história territorial, sobre uma extensa planície aluvionar, resultante de um trabalho conjunto e sucessivo dos rios, do mar, da vegetação dos mangues, dos ventos e dos próprios homens e mulheres habitantes do lugar.

Por isso que não somente se faz necessário analisar a expansão urbana do Recife, em suas diferentes fases históricas, desde a sua formação até o momento presente, como diz a mesma autora; mas, concomitantemente, deve-se levar em conta em que medida, neste processo de expansão, se tem usado os bens coletivos - inclusive os "naturais" presentes no espaço.

Daí a relevância de investigar quem de facto tem tido direito efetivo ao solo urbano, pelo menos às melhores terras ao longo da história urbana na cidade desde a promulgação da Lei de Terras em 1850; esta foi o primeiro instrumento legal de controle do acesso à terra, no Brasil, visando atender os interesses hegemônicos. Ao mesmo tempo, considerar-se-á a complexidade deste processo ao vincular esta nossa preocupação com os processos sociais, econômicos, políticos e culturais, refletindo na face atual do ambiente urbano construído em Recife.

Em outras palavras, nesta pesquisa, refletese sobre o sentido da apropriação - privada - da natureza pelo conjunto dos atores hegemônicos produtores do espaço urbano, com respaldo ou não das ações urbanísticas implementadas pela gestão territorial local, retirando o direito dos demais atores - aqueles pertencentes às classes subalternas - a terem acesso ao solo urbano como um bem 
coletivo essencial à qualidade da sua vida na cidade.

Em princípio, as classes sociais dominantes locais - as de renda mais alta - achamse localizadas nas áreas de maior facilidade construtiva, isto é, naquelas que foram sendo conquistadas às águas no curso da história urbana em Recife em torno do espaço que constituiu o centro histórico-econômico da cidade. O que não significa considerar que parte desse grupo social não esteja, também, buscando fixar-se em outros espaços da área metropolitana de Recife, e nem que não existam populações das classes subalternas locais - as de baixa renda - localizadas no interior das áreas mais abastadas.

A realidade das Zonas Especiais de Interesse Social (ZEIS) demonstra bem o que se acabou de argumentar. Como instrumento legal, introduzido na Lei de Uso e Ocupação do Solo local de 1983, o status de ZEIS (Figura 1) garante a permanência dos seus moradores nestes territórios, mesmo que estejam localizados em áreas de grande valor atribuído pelo CFICF a exemplo das que se localizam em bairros como: Boa Viagem, Boa Vista, Casa Amarela, Pina, Santo Amaro, entre outros. Por outro lado, isto não significa que tais moradores não se achem ameaçados de "expulsão", sobretudo sob o atual contexto de guerra urbana, reativado pelo avanço da lógica da racionalidade técnico-instrumental capitalista, em que vivemos atualmente.

Diante do acima exposto, o objetivo geral deste artigo é, mormente, refletir sobre o uso da natureza em ações urbanísticas a partir do acesso ao solo, indagando sobre quem de facto tem conseguido garantir seu direito ao solo, no curso da história urbana em Recife.

Com isso, destacar-se-á o papel "natural" dos solos, no sítio urbano do município de Recife, identificando os principais atores sociais que, ao longo da história urbana da cidade, tem conquistado seu direito ao solo, como mercadoria; e, ao mesmo tempo, tentar-se-á explicar o processo de privatização do solo na cidade, desconsiderando o direito de todos os recifenses ao solo como um bem coletivo. 


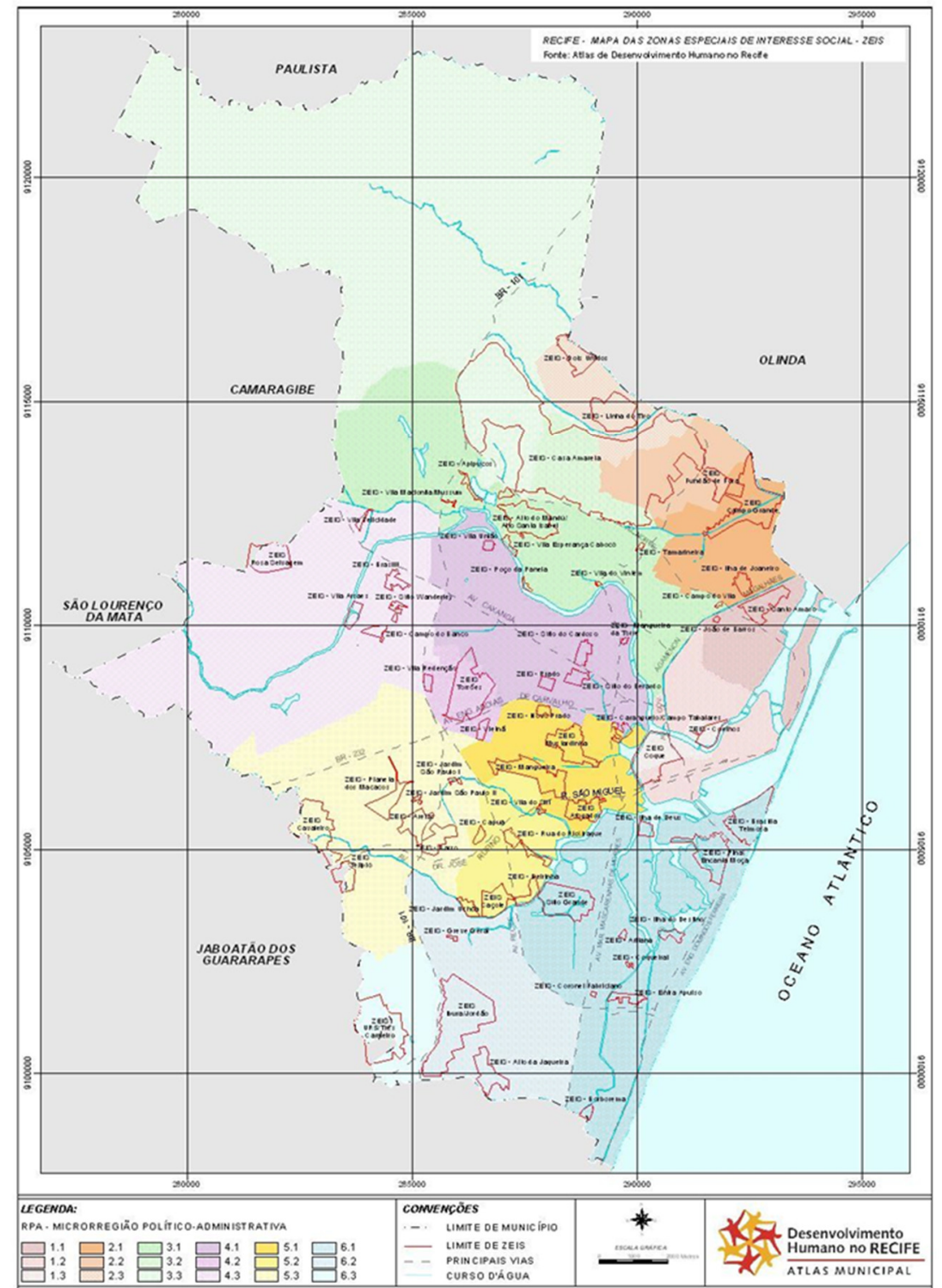

Figura 1. Recife: localização e distribuição territorial das Zonas Especiais de Interesse Social. Fonte: Atlas do Desenvolvimento Humano do Recife (2005).

Na Figura 1 observa-se, claramente, que as diversas áreas destacadas como polígonos no mapa constituem as ZEIS, ou seja, os territórios ocupados, aterrados e construídos pelas próprias pessoas oriundas das classes subalternas, no curso do seu processo territorial de vida na cidade, a fim de garantirem seu acesso ao solo urbano, como fator essencial à continuidade da luta pelo seu direito à cidade. A formação de tais territórios foi, portanto, resultado das diversas formas de mobilização territorial dos movimentos sociais (urbanos) locais, impondo, autonomamente, no âmbito de um conjunto de redes sociais em torno da luta pela terra na cidade, sua própria lógica - a dos territórios vividos - à lógica dos territórios instituídos pela racionalidade técnico-instrumental capitalista.

Se antes, tudo parecia caminhar na direção da concretização da legalização e urbanização dos terrenos ocupados, aterrados e construídos, hoje, com o aguçamento dos interesses inerentes ao

CFICF, de maneira cada vez mais perversa, tais territórios acham-se como que ameaçados de serem apropriados pelas classes dominantes, retirando, assim, o direito de todas as pessoas ao solo como um bem coletivo. Com efeito, tal ameaça está acontecendo, não obstante $o$ fato de que os movimentos sociais continuam a resistir, muito embora tal resistência tenha sido negligenciada e mesmo negada pela mídia oficial a qual, sobretudo no contexto temporo-espacial contemporâneo, tem omitido e mesmo criminalizado as diversas ações de cunho inovador-criativo de mobilização social na cidade e no campo brasileiros. O que ainda se torna muito mais grave em lugares em que o espaço do cidadão ainda não se consolidou como no caso dos territórios brasileiros (Castilho, 2016).

$\mathrm{Na}$ Figura 2 fica patente que, atualmente, grande parte do espaço urbano em Recife, cidade que, para o Instituto Brasileiro de Geografia e Estatística (IBGE), encontra-se totalmente urbanizada, há uma forte competição pelo acesso 
ao solo urbano travada entre as classes dominantes e as classes subalternas, as quais se acham visivelmente territorializadas no espaço urbano local (Figura 3). Enquanto que as classes de maior poder aquisitivo acham-se concentradas em duas porções nítidas do espaço municipal (uma mais ou menos no centro-leste e a outra no sudeste), as de menor poder aquisitivo acham-se dispersas em torno destas duas porções, bem como no seu próprio interior quando, em escalas mais detalhadas, se consegue visualizar nitidamente a presença de significativos assentamentos populares, especificamente favelas e palafitas.
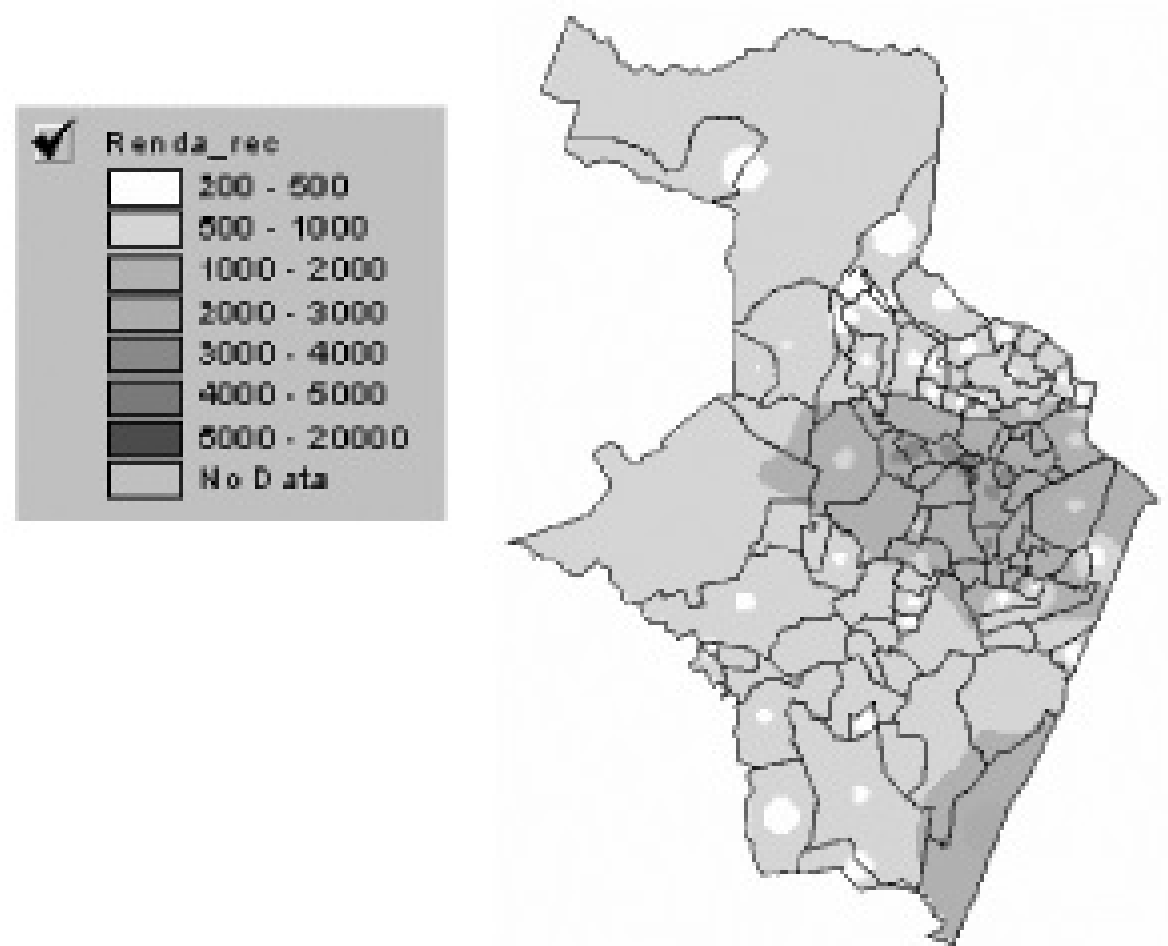

Figura 2. Recife: distribuição da renda, de acordo com o censo 2000 (IBGE). Fonte: arquivo pessoal de Amanda Souza (2017). 

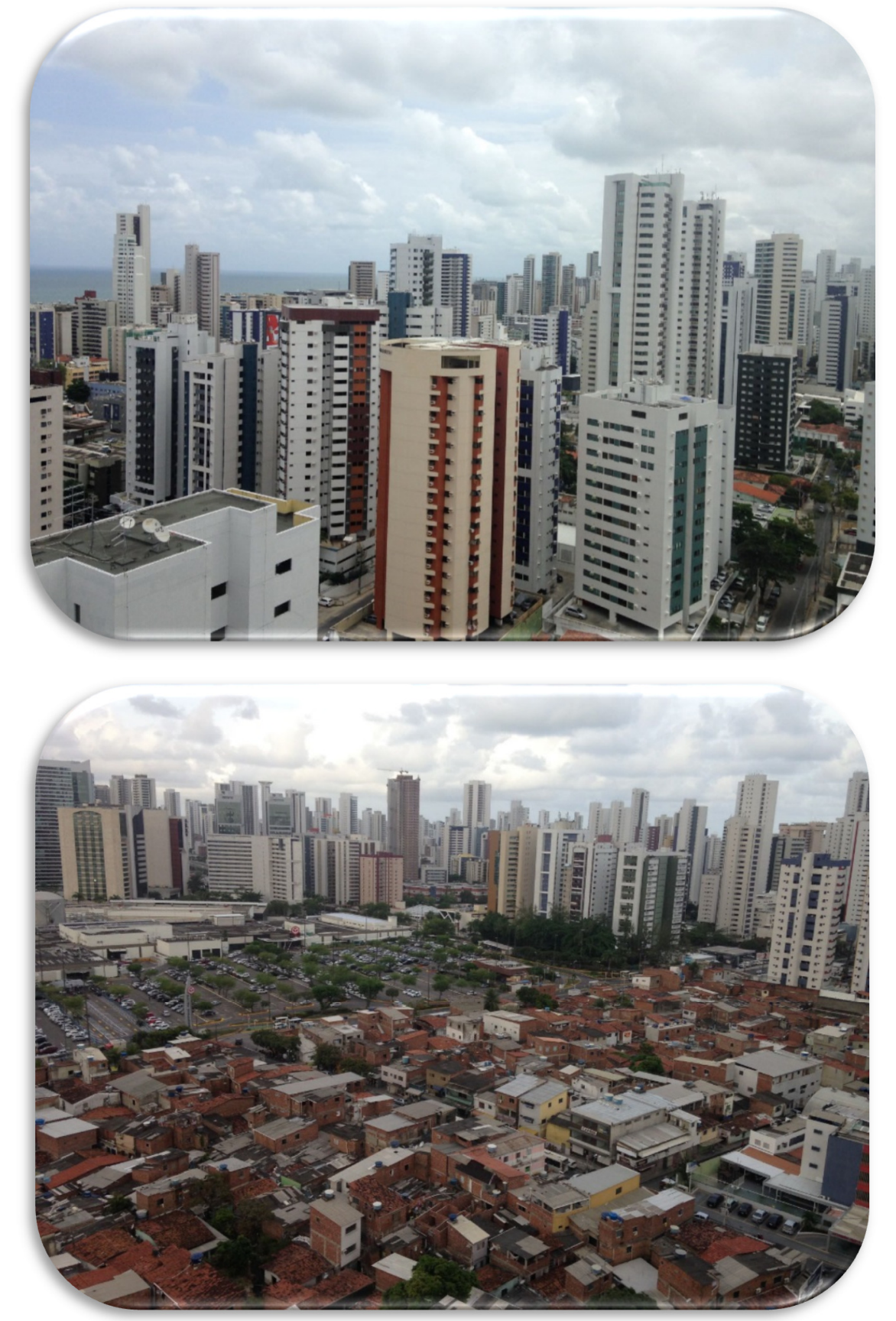

Figura 3. Recife: solo construído de acordo com o nível de renda das classes sociais em processo permanente de luta pela terra urbana. Fonte: Arquivo pessoal de Arthur Teixeira (2017).

Enquanto as classes dominantes residem, predominantemente, nos altos edifícios, constituindo espaços fortemente verticalizados, as classes subalternas residem em construções mais baixas, formando áreas de forte densidade horizontalizada. A Figura 2 mostra que as pessoas pertencentes a estas últimas classes sociais achamse ameaçadas de terem seu direito violado de permanecer nos seus territórios, não obstante a existência de uma legislação social - como a das ZEIS - que lhes garante tal direito. Isso para não mencionar o caso dos assentamentos populares, que ainda não conquistaram o status de ZEIS.

\section{Material e Métodos}

O material utilizado na realização da presente pesquisa é constituído, principalmente, pela literatura existente acerca do tema ora abordado, bem como da dinâmica do processo de uso da natureza - no caso ora especificado, pelo acesso ao solo - em ações urbanísticas remodeladoras do espaço urbano em Recife. Isto, tendo em vista que tais ações ocorrem no âmbito do modelo de desenvolvimento urbano-industrial fundamentado na lógica da racionalidade técnicoinstrumental capitalista neoliberal em uma realidade de região subdesenvolvida, a qual desconsidera tudo o que está presente no território 
que, pelo menos diretamente, não contribua para a acumulação de lucro tais como os pobres e as suas atividades "informais"; o que ocorre de maneira cada vez mais célere e intensa, gerando a conhecida "crise ecológica" em todos os lugares do mundo.

Por outro lado, representada pela redução significativa do potencial ecológico dos lugares que se articulavam aos interesses da lógica supracitada, a crise ecológica foi, entre outras hipóteses, causada, segundo Paolini (2014, p. 9), "[...] por um consumo voraz dos recursos naturais pelos setores da construção civil e da indústria”.

É a natureza profunda deste processo de celeridade do desequilíbrio ambiental nos espaços urbanos que deve ser entendida e deslindada a fim de se buscar soluções efetivamente coerentes com a complexidade inerente à problemática do uso da natureza em ações urbanísticas.

Como a realidade ambiental inerente ao processo de produção do espaço urbano constitui uma totalidade complexa em permanente processo de mudança em algum sentido que sempre é incerto, dependendo das vicissitudes históricoterritoriais dos fenômenos abordados, a presente pesquisa está sendo realizada com base no Paradigma da Complexidade, o qual

[...] pede para pensarmos nos conceitos, sem nunca dá-los por concluídos, para quebrarmos as esferas fechadas, para restabelecermos as articulações entre o que foi separado, para tentarmos compreender a multidimensionalidade, para pensarmos na singularidade com a localidade, com a temporalidade, para nunca esquecermos as totalidades integradoras (Morin, 2000, p. 192)

Isso quer dizer que o problema relativo ao acesso ao solo - pelo seu uso e ocupação - no curso do processo de produção do espaço em Recife, portanto, não é algo isolado do contexto histórico da produção do urbano sob o capitalismo perverso no âmbito das vicissitudes relacionadas às variações dos diversos fluxos do tempo histórico; inclusive tendo fortes vínculos com as formas de uso do espaço pela sociedade brasileira, visando ao atendimento, preponderantemente, de intencionalidades inerentes aos interesses de uma sociedade que se norteia pelo desenvolvimento geográfico desigual.

Além do mais, em função da complexidade supramencionada, somente se poderá compreender a profundidade do problema ora identificado através da adoção de posturas interdisciplinares de uso - ao mesmo tempo, teórico e prático - do espaço, liberando-se de posturas simplistas calcadas na busca do progresso e/ou desenvolvimento descontextualizado no tempo e no espaço. Nesse sentido, o autor considera que "complexidade significa que a ideia de progresso [...] comporta incerteza, comporta sua negação e sua degradação potencial, e, ao mesmo tempo, a luta contra essa degradação" (Morin, p. 97-98). Daí porque, simultaneamente, tem-se que buscar a contextualização de tudo o que existe na terra, juntando os fragmentos - teóricos e empíricos procurando pensar e refletir sobre o Planeta como uma totalidade complexa a ser tratada interdisciplinarmente.

Esta escolha metodológica reside, principalmente, no fato de que uma pesquisa que não se fecha "no local e no particular", como ainda argumenta Morin (2014, p. 97), mas que concebe tais dimensões em seus respectivos conjuntos no âmbito do movimento dialético e dialógico da história, também "estaria apta a favorecer o senso da responsabilidade e o da cidadania" com suas consequências "éticas e cívicas".

Portanto, na busca da concretização desta metodologia ainda não realizada, mas no início da sua execução, pensou-se, como procedimentos metodológicos, as ações de levantamento do quadro natural do uso e ocupação do solo, em Recife, desde as primeiras informações obtidas até o presente momento. Isso realizado a partir de fontes como atlas geográfico e ambiental, centros de pesquisa, bibliotecas, Prefeitura do Recife e seus órgãos públicos, etc.; bem como o levantamento das diversas formas de construção do espaço urbano, cartografando-as a fim de localizar os espaços dos diferentes tipos de atores sociais na cidade, bem como as obras urbanísticas que apoiaram a conquista permanente do solo pelas classes dominantes e médias na cidade. Para este conjunto de ações, pensou-se nas seguintes fontes: Arquivo Público de Pernambuco, bibliotecas, centros de pesquisa, etc.; e ouvir os principais atores do processo de produção do espaço urbano, contemplando o conteúdo das suas falas cujas fontes serão: entrevistas, pesquisa empírica, observação dos ambientes construídos, entre outras.

Para a construção do presente artigo, entretanto, utilizou-se apenas da revisão da literatura acerca da temática ora abordada, bem como as imagens coletadas em pesquisas anteriormente realizadas pelo MSEU e as falas dos moradores.

\section{Resultados}

Primeiramente, o que se faz mais significativo, no que tange ao estudo em 
andamento, é dar visibilidade ao problema do uso da natureza em ações urbanísticas do espaço urbano, e, no caso proposto, pela consideração do acesso ao solo. Considerando este elemento "natural" que, geralmente, as pessoas não enxergam a princípio, mas que é de fundamental importância para a vida da coletividade social, fazse necessário para revalorizar os elementos da "natureza" como bens - e não como meras mercadorias - considerar a complexidade do processo de produção do espaço urbano com a qualidade de vida devida à coletividade dos recifenses.

Outro ponto de suma relevância para esta pesquisa refere-se à necessidade de destacar a importância da posição das pessoas pertencentes a todas as classes sociais, frente ao solo disponível, como um dos fatores fundamentais à promoção da qualidade de vida na cidade, concretizando o direito ao solo para todos.

Em atividades de comunicação junto a territórios vividos, realizadas em Recife, muitos moradores revelaram sua insatisfação com relação ao desrespeito ao seu direito de acesso e uso do seu chão, conquistado e construído por meio de muita luta social, sobretudo a partir de ações apoiadas pelos gestores públicos: “...este espaço, querem tomar de nós...”; “...este terreno é nosso, ninguém deve tirar nosso chão, que também é nosso ganha pão"; “...fomos nós quem construiu tudo isso aqui, pois tudo era mangue antes...”; “...é, a gente construiu tudo isso, e agora quando a terra se valoriza querem tomar de nós, não pode..."; “... é a prefeitura e o governo do estado que deve nos proteger"; "mas se a gente não lutar para isso não vai conseguir nada".

Com efeito, o que se tem visto é a não consideração - e mesmo desobediência - com relação à legislação existente, que garante o direito de todos e todas ao solo, ameaçando, inclusive, a permanência das classes sociais subalternas aos seus territórios historicamente ocupados e construídos por eles mesmos no curso da sua história de vida na cidade, a exemplo do que está acontecendo em ZEIS como Casa Amarela, Coque, Santa Luzia, Santo Amaro, Brasília Teimosa e outras.

Um outro resultado, mas não de menor relevância neste estudo, consiste na contribuição para a revisão das políticas públicas urbanísticas de cunho ambiental na cidade, incentivando a necessidade da utilização de posturas - de pensar e implementar ações urbanísticas no espaço interdisciplinares a fim de melhor compreender e agir na complexidade do problema, ora ressaltado. O que, aliás, deve ter seu início com a valorização dos diversos elementos da "natureza" que nos rodeiam e, dialeticamente, da qual constituímos parte intrínseca.

\section{Discussão}

Visando apropriar-se de elementos, especificamente do solo urbano, foi criado um conjunto de leis; isso ocorreu sobretudo para aprimorar, o que não acontecia desde a promulgação da Lei de Terras, o controle sobre o acesso a tal bem, tornando-o uma mercadoria de interesse preponderantemente do CFICF que tem controlado a dinâmica urbana atualmente. Em Recife, particularmente, de acordo com Alves (2009, p. 123).

Urbanisticamente, a lei de 1919 trata pela primeira vez da repartição da cidade em zonas e expressa um grande preconceito social, no momento em que impõe $o$ afastamento dos mocambos das áreas centrais. A de 1936 ratifica o preconceito social, modifica o zoneamento e impõe a lógica funcional. A lei de 1946 teve a preocupação de dar um maior protagonismo a alguns espaços. Além de ratificar as legislações anteriores, a de 1953 preocupou-se com a modernidade da cidade. $\mathrm{O}$ preconceito social continuou presente na lei de 1961, enquanto buscava o embelezamento da cidade. A lei de 1983 já não expressou o preconceito social e preocupou-se com as condições de urbanização da classe pobre. Preocupou-se também com a pressão imobiliária, definindo zonas urbanas e de expansão urbana. Levouse a cabo a gestão mais democrática da cidade com a criação de um Conselho em que se contemplou a participação da sociedade civil. Em 1989, foi elaborada uma lei específica para alguns bairros, com limitações urbanísticas, a qual influiu bastante nos preços dos imóveis. A lei de 1996 (lei 16.176/96), atualmente em vigor, mudou a estrutura de zoneamento da lei de 1983 e revogou a lei de 1989 , voltando aos preços anteriores. $\mathrm{O}$ mercado imobiliário atua sob o regime destas quatro últimas leis. 
Da mesma maneira, foi também na década de oitenta do século XX que se promulgou a Constituição da República Federativa do Brasil (1988), na qual se destaca o Artigo 225 concernente às políticas do meio ambiente, segundo o qual "Todos têm direito ao meio ambiente ecologicamente equilibrado, bem de uso comum do povo e essencial à sadia qualidade de vida, impondo-se ao Poder Público e à coletividade o dever de defendê-lo e preservá-lo para as presentes e futuras gerações".

Com efeito, tem-se que, em contextos de forte mobilização social, como o que ocorreu, notadamente, no curso dos anos oitenta do século passado, as leis urbanísticas passaram a considerar a presença das classes sociais subalternas no espaço urbano. O que, ao contrário, em contextos históricos de menor mobilização social e, concomitantemente, de maior força dos imperativos da lógica da racionalidade técnicoinstrumental capitalista neoliberal, ocorreram retrocessos, negando as conquistas sociais em termos de direito ao solo urbano para a coletividade social.

É diante de tal situação que se tem indagado alhures em que medida a legislação de cunho mais social é, na verdade, utilizada, em contextos de forte mobilização social, para ludibriar as classes sociais subalternas, fazendo-as crer que tiveram suas necessidades atendidas. Mas que, por outro lado, acabam sendo medidas de controle para dominá-las enquanto classes sociais "perigosas" em estado de animosidade frente às adversidades por elas enfrentadas.

Desse modo, as áreas dos seus territórios permanecem como que em estado de reserva a fim de que possam ser apropriadas pelas classes dominantes nos momentos propícios, muitas vezes facilitado por ações urbanísticas ligadas à realização de grandes eventos internacionais como o que aconteceu em Recife durante a preparação da cidade para sediar parte dos jogos da Copa do Mundo de Futebol realizada em 2014 no Brasil. O que ameaçou muitas áreas da cidade, inclusive ZEIS como Coque dentre outras, suscitando significativos processos de mobilização social.

O problema acima colocado fica patente, principalmente, quando se dá conta de que, não obstante a institucionalização das ZEIS, e mesmo do Plano de Regularização das Zonas Especiais de Interesse Social (PREZEIS), há décadas atrás, os moradores dos referidos territórios ainda não tiveram acesso à efetiva posse da terra e nem a obras cruciais de urbanização da área, constituindo a efetiva inclusão do seu espaço ao da cidade como um todo.
$\mathrm{O}$ pensamento acerca do direito à natureza no campo e na cidade não é algo novo na história da ciência (geografia), uma vez que, desde, principalmente, meados do século XIX, geógrafos, como Reclus - através do seu Do sentimento da natureza nas sociedades modernas - haviam chamado a atenção para a necessidade dos homens e das mulheres reverem as ações e as práticas de destruição da natureza, visando a criação de novas ações e práticas, desta vez recuperadoras da beleza das paisagens.

Outro clássico da geografia, Jean Brunhes, ainda no início do século XX, chamando a atenção das pessoas para o fato de que qualquer ação antrópica impacta no espaço e, portanto, no seu conteúdo - os elementos da "natureza" aí incluídos - defendia que caberia aos homens e às mulheres refletirem sobre a repercussão das suas ações visando controlar seus impactos negativos na perspectiva de se construir um mundo, diríamos hoje, com a sustentabilidade almejada (Castilho, 2017).

E a recuperação da beleza das paisagens pode ter seu início pela democratização do acesso ao solo - junto aos demais elementos da natureza com a concretização da qualidade devida para a coletividade das pessoas que vivem na cidade, e não negando, para alguns, o seu direito a tais elementos como bens essenciais à realização da vida. E isto, lamentavelmente, sempre tem ocorrido através da remoção de famílias dos seus territórios produzidos - que não constituem ZEIS - em áreas do espaço urbano cujos solos foram construídos, através de aterros realizados por eles mesmos no curso da sua história de vida na cidade, inclusive com o respaldo da legislação urbanística de Recife até, pelo menos, os anos oitenta do século XX.

Foi justamente a partir daquele período que se começou a acelerar, também, o processo de destruição da natureza, o que teve continuidade até aos nossos dias a despeito da existência de leis que a protegem. Recife presenciara, também naquele período, o início da negação e mesmo supressão das águas e do verde, em favor do crescimento urbano sem limites (Castilho, 2014). Hoje em dia, tem-se algo mais substancial no que se refere ao entendimento e à garantia da natureza como direito social, o que se reforça com

[... uma preocupação na
superação da utilização da
natureza como um processo de
satisfação individual, vinculado ao
consumismo [da 'propaganda
verde'], através da construção de
um processo de ação e uso da
natureza como uma forma de
emancipação coletiva,


constituindo no mundo contemporâneo, um direito à natureza na cidade para todos os seus habitantes (Henrique, 2009, p. 14).

Por isso, as políticas urbanísticas conjunto de ações sociais que acontecem no espaço urbano, implementadas pelos principais agentes produtores do espaço urbano - devem prestar bem atenção para esta questão. Na medida em que se tratam de ações que, em sua complexidade, constituem os principais instrumentos com os quais os agentes públicos e privados organizam os seus territórios e as suas territorialidades, tecendo, enfim, os diversos ambientes nos quais, mesmo sem ter muito a ver com as necessidades efetivas das pessoas, estas têm que viver, trabalhar, brincar, etc.

Tal fato acontece no contexto em que os territórios vividos, segundo Frémont (1999), são alienados a fim de obedecer aos imperativos da racionalidade técnico-instrumental capitalista do CFICF, hoje neoliberal, a qual, possui como propósito precípuo transformar o espaço - e tudo o que ele contém - em mercadoria a ser vendida no mercado imobiliário a fim de acelerar o processo de geração de valores puramente econômicos, que é a meta essencial do modo de produção capitalista. Isso acontecendo no âmbito dos embates permanentes entre os interesses que impõem a expansão dos "territórios do capital" sobre os "territórios dos povos", tal como refletiu Leroy (2010) sobre a realidade na Amazônia brasileira.

Urge, então, fazer um esforço no sentido de, pelo menos, recuperar o equilíbrio entre tais interesses e, ao mesmo tempo, levando em conta o princípio da natureza em todas as ações urbanísticas para o que, aliás, tem-se que controlar o atual uso acelerado da natureza. Sabe-se que, no mundo, existem experiências de revalorização da natureza em práticas urbanísticas atuais, tais como aquelas existentes no estudo de Dorier-April (2006).

No caso específico do solo urbano, por exemplo, segundo Higueras (2010, p. 81), os poderes públicos têm grande responsabilidade e dever de controlar o seu uso, pelo planejamento urbano. Em assim sendo,

Los factores del suelo que se deben tomar en consideración desde la planificación son los siguientes:

- Que el suelo tenga buena capacidad portante.

- Evitar la construcción en zonas permeables o de recarga de acuíferos subterráneos.
- No pavimentar en exceso los espacios libres o la red viaria, estableciendo en el viario local, parques y espacios libres zonas más permeables que ayuden a permitir el almacenamiento de agua en el subsuelo, con los subsiguientes efectos beneficiosos para la vegetación, para aumentar el grado de humedad en el medio ambiente y para posibilitar la recarga de los acuíferos.

- Evitar problemas específicos del subsuelo, como la presencia de fosfatos, carbonatos, yesos o arcillas, que puedan afectar a la cimentación y a la estabilidad de los inmuebles.

Antes de tudo isso, sobretudo em espaços urbanos de países como o Brasil, faz-se mais urgente, principalmente, a garantia do acesso ao solo como um bem a ser utilizado em benefício do bem-estar e do bem-viver da coletividade social em qualquer lugar do Planeta.

Paralelamente, não se deve retirar o direito de todas as pessoas a estarem próximas da natureza em função, sobretudo, da positividade no que tange a esta proximidade em termos de qualidade de vida que representa esta aproximação. Em outras palavras, além de terem que levar em conta o princípio da natureza, tal como sugerido por Louv (2014), em seus processos de implementação, as ações urbanísticas devem também superar a cultura do institucionalismo transcendental, ou seja,

[...] também temos de pensar em como as instituições devem ser criadas aqui e agora, para promover a justiça reforçando as liberdades negativas $\mathrm{e}$ substantivas, bem como o bemestar das pessoas que vivem hoje e que amanhã terão partido. (Sen, 2011, p. 111)

Nesta perspectiva, as ações urbanísticas, como políticas públicas capazes de promover o desenvolvimento territorial em todas as suas dimensões, deveriam ser efetivamente públicas, reaproximando-se cada vez mais das pessoas que são negligenciadas pela "economia formal", e exercendo o permanente diálogo com seu povo de maneira a contemplar o que tem origem nas diversas territorialidades da cidade. O que, se demandado por movimentos sociais fortes, seguramente, acontecerá.

Para o que, segundo o mesmo autor acima citado, os direitos humanos, tal como o direito a ocupar o solo urbano, podem servir como 
inspiração. E, claro que fundamentando, como argumenta Pontes (2017), uma nova práxis direcionada à concretização de outra racionalidade, talvez a ambiental idealizada por Leff (2009).

A proximidade com relação ao solo como direito de todos pode também ser pensada e praticada de maneira a se conquistar o conforto ambiental para todos e todas na cidade, na medida em que promove espaços de amenidades contra os modificados pelo homem na perspectiva do mercado os quais, pela própria tendência da expansão urbana atual, ou seja, sem limites e controle, tende a crescer.

Acredita-se que a reaproximação entre sociedade e natureza é, portanto, de fundamental importância para o desenvolvimento territorial do estado de Pernambuco, assim como em todo o território nacional. Isso porque, o cuidado e a consideração para com os elementos da natureza na cidade não somente promovem, em seu conjunto, o desenvolvimento social como, concomitantemente, o desenvolvimento econômico.

\section{Conclusão}

Do mesmo modo como ocorre com o acesso à água, ao verde e aos ventos marítimos, o acesso ao solo tende a ser privatizado em benefício das classes dominantes, nas cidades cuja dinâmica territorial norteia-se pelos imperativos da lógica da racionalidade técnico-instrumental capitalista, hoje neoliberal.

Nesse contexto, às classes subalternas resta, se não estiverem atentas e demasiadamente organizadas e articuladas, apenas se adaptarem aos efeitos perversos da referida lógica, ocupando os espaços que sobram no embate propiciado pela cobiça liderada pelos interesses do CFICF, os quais, ao mesmo tempo, se sustentam na fábula da legislação social.

A despeito de se ter instituído uma legislação de cunho social, desde a escala nacional à local, no curso da história urbana no Brasil, os direitos - inclusive à "natureza" como bem coletivo - conquistados pela sociedade acham-se, no presente momento, desrespeitados. Isso ocorre em nome do crescimento econômico a todo custo, o qual, em vez da manutenção dos ambientes belos (representados por paisagens que se nos aparecem respeitando os parâmetros da sustentabilidade almejada), tecem ambientes feios (representados pela destruição insensata da "natureza" que se nos apresenta, portanto, insustentável à vida).

Enfim, faz-se necessário retomar as mobilizações territoriais em torno da luta pela terra visando fazer valer o respeito à legislação socialmente instituída, com base em um saber ambiental que sustente uma outra lógica de pensar e atuar, indo ao encontro, talvez, de uma contraracionalidade, ou seja, de uma racionalidade ambiental.

\section{Agradecimentos}

Agradecemos ao Conselho Nacional de Desenvolvimento Científico e Tecnológico $(\mathrm{CNPq})$, pela bolsa de produtividade concedida ao Professor Cláudio Jorge Moura de Castilho, bem como pela bolsa de iniciação científica concedida à estudante Amanda Cristina Perboire Emerenciano de Souza, respectivamente, primeiro e segundo autores.

\section{Referências}

ALVES, P. R. M. 2009. Valores do Recife. O valor do solo na evolução da cidade. Recife: Luci Artes Gráficas Ltda.

BARRETO, A. M. M. 1994. O Recife através dos tempos: formação da sua paisagem. Recife: Edições Fundarpe.

BRASIL. 1988. Constituição da República Federativa do Brasil. Brasília: Editora Mandarino.

CASTILHO, C. J. M. DE. 2014. Água e espaço urbano em Recife. Interesses sociais e geopolítica interna. Revista Brasileira de Geografia Física, v. 07, n. 03, p. 597-614.

. 2016. Justiça ambiental: uma tarefa difícil em contexto territorial de ausência do espaço do cidadão. Revista Movimentos Sociais \& Dinâmicas Espaciais, v. 5, n. 1, p. 7-34.

2017. Jean Brunhes: a atualidade de um geógrafo do início do século XX. Revista Movimentos Sociais \& Dinâmicas Espaciais, v. 6, n. 1, p. 253-272.

; TEIXEIRA, A. F. DE M. 2016. O uso da natureza no processo de construção do urbano: quem tem tido direito aos ventos marítimos em Recife-Brasil? Journal of Environmental Analysis and Progress, v. 1, pp. 13-23.

CASTRO, J. DE. 1954. A Cidade do Recife. Ensaio de Geografia Urbana. Rio de Janeiro: Livraria Editora da Casa do Estudante do Brasil.

CRIEKINGEN, M. V. 2006. A cidade revive! Formas, políticas e impactos da revitalização residencial em Bruxelas. In: BIDOUZACHARIASEN, C. De volta à cidade. Dos processos de gentrificação às políticas de 
"revitalização" dos centros urbanos. São Paulo: Annablume, pp. 89-120.

DORIER-APRIL, E. (org.) 2006. Ville et environnement. Paris: Sedes.

FRÉMONT, A. 1999. La région espace vécu. Paris: Flammarion.

HENRIQUE, W. 2009. O direito à natureza na cidade. Salvador: Edufba.

HIGUERAS, E. 2013. Urbanismo bioclimático. Madrid: Editorial Gustavo Gili.

LEFF, E. 2009. Saber ambiental. Sustentabilidade. Racionalidade. Complexidade. Poder. Petrópolis: Vozes.

LEROY, J. P. 2010. Territórios do futuro. Educação, meio ambiente e ação coletiva. Rio de Janeiro: Lamparina.

LINS, R. C. 1982. Alguns aspectos originais do sítio urbano do Recife. In: ANDRADE, M. C. DE. (org.). Capítulos de geografia do Nordeste. Recife: União Geográfica Internacional - Comissão do Brasil, pp. 81-85.

LOUV, R. 2014. O princípio da natureza. Reconectando-se ao meio ambiente na era digital. São Paulo: Cultrix.

MELO, M. L. DE. 1978. Metropolização e subdesenvolvimento. O caso do Recife. Recife: Editora da Universidade Federal de Pernambuco.

MORIN, E. 1999. Por uma reforma do pensamento. In: PENA-VEGA, A.; ALMEIDA, E. P. de. (Org.) O pensar complexo: Edgard Morin e a crise da modernidade. Rio de Janeiro: Garamond.

Janeiro: Bertrand Brasil.

2014. A cabeça bem-feita: repensar a reforma, reformar o pensamento. $21^{\mathrm{a}}$ ed. Rio de Janeiro: Bertrand Brasil.
RECLUS, E. 2010. Do sentimento da natureza nas sociedades modernas. São Paulo: Expressão \& Arte: Editora Imaginário.

SEN, A. 2011. A ideia de justiça. São Paulo: Companhia das Letras.

OLIVEIRA, L. J. DE. 2017. Análise dialéticomaterialista da estruturação natural das paisagens contidas na porção centro-oriental de Pernambuco. Tese (Doutorado em Desenvolvimento e Meio Ambiente), Programa de Pós-Graduação em Desenvolvimento e Meio Ambiente), Universidade Federal de Pernambuco, Recife.

PAOLINI, F. 2014. Firenze 1946-2005. Una storia urbana ambientale. Milano: Franco Angeli, 2014.

SOEIRO, I. C. DE M.; CASTILHO, C. J. M. DE. 2015. O caráter ideológico da natureza e o processo de produção do espaço em Tejipió/Recife. Revista Brasileira de Geografia Física, v. 8, n. 1, p. 221235.

PONTES, B. A. N. M. 2017. Desenvolvimento e governança ambiental: em busca de uma outra práxis na dinâmica territorial da Reserva do PaivaPE. Dissertação (Mestrado em Desenvolvimento e Meio Ambiente), Universidade Federal de Pernambuco, Recife.

PONTES, B. A. N. M.; CASTILHO, C. J. M. DE. 2016. O conceito e a instrumentalização da natureza: olhares transversais na dinâmica territorial da Praia do Paiva-PE. Revista Brasileira de Geografia Física, v. 9, p. 852-867.

SOEIRO, I. C. DE M.; WERTHEIMER, M.; BAUTISTA, D. C. G.; CASTILHO, C. J. M. DE. 2016. O uso da retórica ecológica na produção do espaço urbano em cidades latino-americanas: uma revisão da literatura. Revista Movimentos Sociais \& Dinâmicas Espaciais, v. 5, n. 2, p. 284-310.

SOEIRO, I. C. DE M. 2017. Reaproximação forjada da natureza: a utilização da retórica ecológica na produção do espaço urbano de uma cidade latino-americana. Dissertação (Mestrado em Desenvolvimento Urbano), Programa de PósGraduação em Desenvolvimento e Meio Ambiente, Universidade Federal de Pernambuco, Recife. 